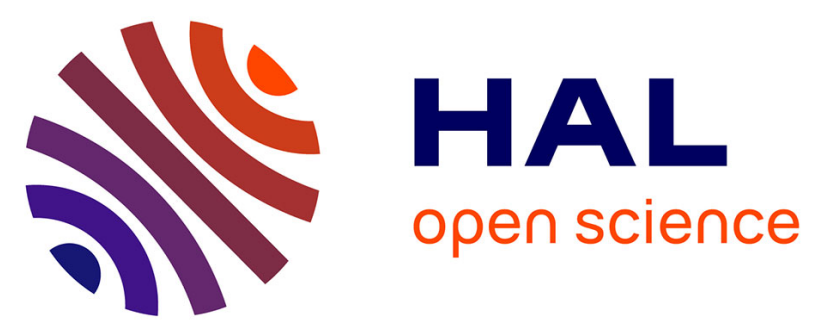

\title{
Beneficial effects of offering prenatal HIV counselling and testing on developing a HIV preventive attitude among couples. Abidjan, 2002-2005.
}

\author{
Annabelle Desgrées Du Loû, Hermann Brou, Gérard Djohan, Renaud \\ Becquet, Didier K. Ekouevi, Benjamin Zanou, Ida Viho, Gérard Allou, \\ François Dabis, Valériane Leroy, et al.
}

\section{To cite this version:}

Annabelle Desgrées Du Loû, Hermann Brou, Gérard Djohan, Renaud Becquet, Didier K. Ekouevi, et al.. Beneficial effects of offering prenatal HIV counselling and testing on developing a HIV preventive attitude among couples. Abidjan, 2002-2005.: Beneficial effects of offering prenatal HIV counselling and testing. AIDS and Behavior, 2009, 13 (2), pp.348-55. 10.1007/s10461-007-9316-6 . inserm00172484

\section{HAL Id: inserm-00172484 https://www.hal.inserm.fr/inserm-00172484}

Submitted on 7 Nov 2007

HAL is a multi-disciplinary open access archive for the deposit and dissemination of scientific research documents, whether they are published or not. The documents may come from teaching and research institutions in France or abroad, or from public or private research centers.
L'archive ouverte pluridisciplinaire HAL, est destinée au dépôt et à la diffusion de documents scientifiques de niveau recherche, publiés ou non, émanant des établissements d'enseignement et de recherche français ou étrangers, des laboratoires publics ou privés. 
Beneficial effects of offering prenatal HIV counselling and testing on developing a HIV preventive attitude among couples . Abidjan, 2002-2005.

\section{Runing head : Beneficial effects of offering prenatal HIV counselling and testing}

Authors : Annabel DESGRÉES-DU-LOU ${ }^{1}$, Hermann BROU ${ }^{1,2}$, Gérard DJOHAN ${ }^{2}$, Renaud BECQUET ${ }^{3}$, Didier K. EKOUEVI ${ }^{4}$, Benjamin ZANOU ${ }^{2}$, Ida VIHO ${ }^{4}$, Gerard ALLOU ${ }^{4}$, Francois DABIS ${ }^{3}$, Valériane LEROY ${ }^{3}$, ANRS 1201/1202/1253 Ditrame Plus study group *

Affiliations :

${ }^{1}$ UMR 151, IRD, France

${ }^{2}$ Projet ANRS 1253 Ditrame Plus, Ecole Nationale Supérieure de Statistiques et d'Economie Appliquée (ENSEA), Abidjan, Côte d'Ivoire

${ }^{3}$ Unité INSERM 593, Institut de Santé Publique Epidémiologie et Développement (ISPED), Université Victor Segalen, Bordeaux, France

4 Projet ANRS 1201/1202 Ditrame Plus, Programme PAC-CI, Centre Hospitalier Universitaire de Treichville, Abidjan, Côte d'Ivoire

* See appendix

Correspondence and reprint requests

Annabel Desgrées-du-Loû,

37 rue d'Amsterdam

75008 Paris

Tel : $0033143947290 \quad$ Fax : 0033143947292

Email : annabel.desgrees@ird.fr ; annabel.desgrees@free.fr 


\section{ABSTRACT (163 words)}

Prenatal HIV counselling and testing is mainly an entry-point to the prevention of mother-tochild transmission of HIV, but it may also play an important role in triggering the development of spousal communication about HIV and sexual risks and thus the adoption of a preventive attitude.

In Abidjan, Côte d'Ivoire, we investigated couple communication on STIs and HIV, male partner HIV-testing and condom use at sex resumption after delivery among three groups of pregnant women who were offered prenatal counselling and HIV testing : HIV-infected women, uninfected women, and women who refused HIV-testing.

The proportion of women who discussed STIs with their regular partner greatly increased after prenatal HIV counselling and testing in all three groups, irrespective of the women's serostatus and even in the case of test refusal. Spousal communication was related to more frequent male partner HIV-testing and condom use.

Prenatal HIV counselling and testing proposal appears to be an efficient tool to sensitize women and their partner to safer sexual practices.

KEY-WORDS : prenatal HIV counselling and testing, couple, HIV/STIs, Africa, prevention 


\section{Introduction}

In Africa, the prevention of heterosexual HIV transmission has not yet reached the coverage and intensity required by the magnitude of the pandemic (Bunnell, Mermin, \& De Cock, 2006). This is particularly true between regular sexual partners, among whom the adoption of consistent preventive behaviours remains largely insufficient (Van Rossem, Meekers, \& Zkinyemi, 2001). The development of HIV prevention strategies targeting couples as well as individuals seems increasingly relevant to improving the prevention of unsafe sexual behaviours. A large percentage of new infections in Africa occur within the couple, through the sexual transmission of HIV between regular partners (UNAIDS, 2006). It is indeed within the married couple that the use of condoms remains most problematic. Condoms are frequently associated with the idea of occasional sexual intercourse (Van Rossem et al., 2001). For most married men and women, condom use appears to be relevant for preventing sexual risks in extramarital partnership (Chimbiri, 2007). It is not well accepted in sexual relations within stable couples (Bond \& Dover, 1997; Hogsborg \& Aaby, 1992). Painter suggests that, to improve the use of condoms within married couples, one needs to take into account how the couple communicates about condom use, and not only the couple's knowledge of condoms or condom availability (Painter, 2001). Dialogue within couples may be indeed considered as a prerequisite to a change in sexual behavior, as it has been observed to be for family planning (Babalola, 1999).

Services meant to prevent mother-to-child transmission of HIV (PMTCT) are now available at moderate cost in most countries affected by the HIV/AIDS epidemic (Ekouevi, TonweGold, \& Dabis, 2005) and may play an important role in risk reduction strategies within the couple. The first step of these PMTCT interventions providing antiretroviral drugs consists of systematically offering HIV counselling and testing to pregnant women attending antenatal care services. In the African context, HIV-testing has until now remained unfrequent (UNAIDS, 2006). Development of PMTCT programs will improve the access to and 
coverage of HIV counselling and testing, reaching women who would not access HIV testing otherwise (De Cock \& Grubb, 2006). But women who are offered counselling and HIV testing in antenatal consultation are often the first to be counselled and HIV-tested within their couple. These women are thereafter advised to share their counselling with their partner. They become responsible for encouraging him to get tested for HIV and to develop a preventive attitude towards HIV/AIDS. For HIV-negative women, leading their partner to such an attitude is an important condition to preserve their negative HIV-status (McIntyre, 2005).

In this paper, we investigated with a quantitative study the effect of offering such prenatal counselling and testing on couple communication about STIs, HIV, and sexual risk prevention among three groups of women in a West-African city : HIV-positive, HIVnegative and those who refused to be HIV-tested.

\section{Population and Methods}

\section{Study population and design}

Our study took place within a multidisciplinary PMTCT research programme, ANRS DITRAME PLUS, conducted in Abidjan, Côte d'Ivoire, from 2001 to 2005. Among the services provided, prenatal counselling and HIV testing was systematically offered to every pregnant women attending seven antenatal clinics in Abobo and Yopougon (Ekouevi, Leroy, Viho, \& al., 2004). These two districts are located in Abidjan, the economic capital of Côte d'Ivoire. Women who accepted the HIV test and who were HIV-infected entered the PMTCT programme fully described elsewhere (Becquet, Ekouevi, Viho, \& al., 2005; Dabis, Becquet, Ekouevi, \& al., 2005) and were followed-up during two years after the delivery.

HIV-negative women and women who refused to be tested for HIV were offered a reproductive health oriented follow-up, with one visit to the health center every six months for the two years following the delivery. No monetary incentive was offered to the 
participating women, other than the reimbursement of transportation fees. But mother-infant pairs had access to free health care services, regardless of their HIV status. Women were encouraged to suggest HIV testing to their partner and free HIV counselling and testing was provided to the women's partners and relatives who requested it.

\section{Data collection}

At the time when the counselling and testing were offered, we collected data on women's socio-demographic characteristics and on condom use, communication with the partner about STIs, and partner HIV testing during the two years preceding the current pregnancy. During each follow-up visit, standard questionnaires were administered to all women to document the resumption of sexual activity after delivery. Among women who performed their 18month post-partum visit between February 2004 and February 2005, data were collected on communication with the partner regarding HIV and sexual risks, on condom use at sex resumption and on HIV-testing of the male partner since the initial offer of the HIV-test. We asked women if they had discussed STIs with their partner at least once since the test offer, if they disclosed their HIV-test result to their partner, if they suggested at least once to their partner to undertake HIV testing, and if they suggested their partner to use condoms if he had extraconjugal intercourse. Condom use at sex resumption was collected from the following question : "since last visit, if you resumed sexual activity, did you use condom ? Answer 1: no, answer 2 : yes, sometimes, answer 3 : yes, systematically".

The same structured, close-ended questionnaires were administered to the HIV-infected women (participating in the PMTCT programme) as the HIV-uninfected women and the women who refused to be HIV-tested (participating in the reproductive health follow-up). Questionnaires were administered during individual 40-minute-long interviews, in private rooms to secure maximum confidentiality, by specially trained social workers and midwives participating in the program. 


\section{Statistical analysis}

Baseline socio-demographic characteristics of the three groups of women were described and compared with the Pearson Chi-square test.

Proportions of women who had discussed STIs with their partner prior to and following prenatal offer of counselling and HIV-testing were compared with a McNemar test. We also compared with a McNemar test the proportion of women who reported having ever used condoms with their regular partner within the two years preceding the pregnancy and the proportion of women who declared they used condoms (sometimes or systematically) when they resumed sexual relations after delivery.

A Pearson Chi-square test was used to compare indicators of conjugal communication about sexual risks between HIV positive and HIV negative women, and between HIV negative women and women having refused to be tested. We analysed the effect of these indicators of conjugal communication adjusted on HIV-status and socio-demographic variables on the probability that the partner had been HIV-tested over the study period using logistic regression with stepwise descendant procedure.

We analysed how religion, education, partner HIV testing and communication about sexual risks within couples were related to frequency of systematic condom use at sex resumption, for each HIV-status. The significance of these relations were measured by a Pearson Chi 2 test.

\section{Results :}

Between August 2002 and August 2003, 475 HIV-infected women, 400 HIV-negative women and 62 untested pregnant women entered the programme. Of these, $128(26.7 \%), 45$ $(11.3 \%)$ and $10(16.1 \%)$ did not perform their 18-month post-partum visit, leaving 347 HIVinfected, 355 HIV-negative and 52 untested women. For this couple-centered study, we 
excluded $41 \mathrm{HIV}$-infected women and $3 \mathrm{HIV}$-negative women since they did not declare any regular partner at any moment of the follow-up.

No differences in education level and religion were observed between HIV-infected and HIV negative women (see Table 1). Compared to HIV-negative women, HIV-infected were slightly older and more often in polygamous union, and on average they had had their first sexual intercourse half a year earlier. The group of women who refused to be HIV-tested was similar to the HIV-negative group for age and age at first intercourse, but had a higher education level than the women tested for HIV. Most of these untested women were christians and in monogamous unions. The women who refused to be HIV tested had not been previously tested.

\section{Couple communication on sexual risks}

Indicators of communication about sexual risks were quite similar between HIV-negative women and women who refused to be tested, for both periods (see Table 2). Two-thirds of the women from these two groups had ever discussed STIs with their regular partner during the two years preceding the index pregnancy. After prenatal counselling and testing, more than $90 \%$ of them had discussed STIs with their partner, and suggested their partner that he should undertake HIV testing and use condoms in case of extraconjugal relationships. This increase was significant $(\mathrm{p}<0.01, \mathrm{Mc}$ Nemar test) for each group.

Among HIV-infected women, indicators prior to prenatal counselling and testing suggest less communication about sexual risks between partners : only $28 \%$ had discussed STIs with their regular partner during the two years preceding the index pregnancy (see Table 2). After prenatal counselling and testing, despite the fact that $57 \%$ of these women had not disclosed their HIV result to their partner, $65 \%$ of HIV-infected women discussed STIs with their partner (an increase of $37 \%, \mathrm{p}<0.01$, Mc Nemar test), $72 \%$ suggested their partner that he 
should be HIV-tested, and 58\% suggested the partner to use condoms in case of extraconjugal relationships.

At the end of the survey, among the 62 women who had refused the prenatal proposition of HIV testing and who entered the study, $11(18 \%)$ accepted to be tested when they were reproposed. One among 11 was HIV infected.

\section{HIV testing of the partner over the post-partum period}

When entering the programme, 41 women had a male partner already HIV-tested (26 HIVinfected women, 13 HIV-negative women and 2 women having refused to be tested). During the follow-up, among male partners not previously tested, $25 \%$ of the partners of HIVinfected women, $13 \%$ of the partners of HIV-negative women and $6 \%$ of the partners of untested women performed an HIV-test (see Table 3). After adjustment, the only variables associated with the partner's HIV-testing during follow-up were the fact that the woman had suggested her partner to get an HIV-test $(\mathrm{OR}=4.0$ [1.5-10.8]), the woman's HIV-infection status and living in individual rather than shared housing (see Table 3).

\section{Condom use}

In the two years prior to the test proposal, $36 \%$ of HIV-negative women and $52 \%$ of untested women had used condoms at least once. When they resumed sexual relations after delivery, these proportions increased to $59 \%$ and $57 \%$ (see Table 2). The increase was significant for HIV-negative women ( $<<0.01$, Mc Nemar test). Among HIV-infected women, only $23 \%$ had used condoms at least once with their regular partner during the two years preceding the index pregnancy. After prenatal counselling and testing, 49\% used condoms when they resumed sexual activity (an increase of $26 \%, p<0.01$, Mc Nemar test).

When considering only "systematic condom use" after delivery, levels were lower : one couple out of three used condoms when the woman was HIV-infected or had refused to be tested, and $27 \%$ when the woman was HIV-tested and negative. For HIV infected women, 
discussing STIs with the partner and suggesting him to undertake its HIV-testing was associated with a better systematic use of condoms. Condom use was more frequent when the male partner had been HIV-tested and it was maximum when both partners were HIVinfected (see Table 4). For HIV-negative women and those who refused the HIV-test, the few women who did not discuss these topics with their partner did not use condom at sex resumption (see Table 4).

\section{Discussion}

In this study we observed that the prenatal offer of HIV counselling and testing is followed by a high level of communication about HIV and/or sexual risks between women and their regular partners, irrespective of the women serostatus and even in the case of test refusal. This spousal communication about HIV and/or sexual risks, when it existed, was related to more frequent male partner HIV-testing and condom use at sex resumption after delivery.

A limit of our study is that we conducted it within a population participating in a research program offering systematic prenatal HIV testing and counselling but not in the operational context of PMTCT services delivery. The effect of prenatal HIV counselling and testing documented here is thus likely to have been higher than what would have been observed within the national programme where free and continuous counselling, follow-up and support of women are not provided. However, this setting enabled us to observe a strong effect of prenatal HIV counselling and testing on postnatal spousal communication and on AIDS preventive attitude, with reliable informations resulting from the controlled anteriority of HIV-testing. Hence conclusions drawn from this specific context may be useful to other operational contexts. Another limit of our study is that we could only collect self-reported data from women, and none from their partners. Thus, our data may suffer from overestimation due to positive self-representation on the part of women. Nevertheless, this may have equally affected all the women participating in the survey and thus may not be a 
source of bias. Moreover, previous surveys conducted in the same population showed that there are very few taboos in this population concerning sexuality that could have lead to information bias. Women answer usually easily on these subjects (Desgrees-du-Lou \& Brou, 2005; Desgrees-Du-Lou et al., 2002).

Previous studies have shown a beneficial effect of voluntary counselling and testing regarding prevention of sexual risks (Allen, Meinzen-Derr, Kautzman, Zulu, \& Trask, 2003; DiFranceisco Wayne, Pinkerton Steven, Dyatlov Roman, \& Geoffrey, 2005), but few have dealt with prenatal counselling and testing systematically offered to pregnant women. Nevertheless, counselling to develop safer sex practices is essential during pregnancy and the post-partum period, which place women at high risk of HIV infection for hormonal and behavioural reasons (Cleland, Ali, \& Capo-Chichi, 1999; Gray et al., 2005; Leroy et al., 1994). When available, most studies on prenatal counselling and testing concern only HIVinfected women (Medley, Garcia-Moreno, McGill, \& Maman, 2004). Limited information is available on the role of prenatal counselling and testing for HIV-negative women or women who refuse the test. Our figures confirm the beneficial effect of prenatal counselling and testing when the woman is HIV-infected, and also reveal a positive effect of this prenatal counselling and testing for pregnant women uninfected or who refuse to be tested.

We assessed the beneficial effect of prenatal HIV counselling and testing not only by indicators of protection of sexual intercourse and male partner HIV-testing but also by the spousal communication regarding sexual risks. Family planning studies have shown a strong positive correlation between spousal commmunication and contraceptive use (Babalola, 1999; Dodoo, 1998; Ezeh, 1993). This positive relationship between spousal communication and contraceptive use suggests the potential importance of spousal communication in AIDS prevention. The few studies available on this subject confirm a positive relationship between partner communication and condom use (Zamboni, Crawford, \& Williams, 2000). HIV 
prevention is greater among couples where there is a spousal discussion of HIV issues (Bühler \& Kohler, 2003). Our results confirm a positive relationship between spousal communication about HIV or STIs and preventive behaviour towards AIDS (condom use, HIV testing of male partner). Moreover, our study points out that prenatal counselling and testing is a good "stimulus factor" (as it has been described in (Zulu \& Chepngeno, 2003) to develop this spousal communication about AIDS and sexual risks. This conjugal talk on sexual risks is accompanied by an increase in condom use if comparing to the level measured before the pregnancy. When considering "systematic condom use", levels obtained remain too low to ensure an efficient prevention of HIV transmission in the couple. Nevertheless it is a progress if comparing to condom use level measured in the general population : in the last Demographic and Health survey in this country, less than $2 \%$ of "in union" women and $7 \%$ of "in union" men used a condom at the time of the survey ((INS) \& Macro, 2001).

Eventually, our study gives a unique comparison between three groups of women : HIVinfected women, HIV-negative women and those who had refused to be tested for HIV. For women aware of their HIV infection, the lower level of spousal communication about HIV, compared to HIV-negative women, suggests that discussions related to HIV/AIDS in general and to their own HIV-status in particular were perceived as risky, related to the fear of being rejected by their partner (Medley et al., 2004) (even though the data collected within our study only documented a few cases of notified rejection). Nevertheless, our figures revealed that despite this fear, HIV-infected women engaged in a discussion of HIV after testing. Only $38 \%$ of them disclosed their serostatus to their partner, but $72 \%$ suggested that the partner get tested for HIV, and the proportion of women who discussed STIs with their partner doubled after counselling and testing.

For HIV-negative women, the effect of prenatal HIV counselling and testing, clearly positive in terms of inducing communication within the couple about STIs and HIV, was more 
moderate in terms of effective prevention strategies. Only a small proportion of partners decided to be HIV-tested and one couple in four reported systematically protected sexual intercourse. We described in a previous study conducted among HIV-negative women how their partners don't practise their own HIV-test because they often consider the woman's HIV-status to be an indicator of their own HIV-status (Brou, Agbo, \& Desgrees Du Lou, 2005). This misconception is largely refuted by the prevalence of HIV discordant couples in Africa (Allen et al., 2003; Kilewo, Massawe, Lyamuya, Semali, \& Kalokola, 2001). These findings highlight the need to strengthen the counselling component targeted to HIV-negative women. It is necessary to improve counselling regarding the partner's HIV testing and the use of condoms until the partner has been HIV-tested. This counselling is even more critical after he has been identified as HIV-infected.

The experience of women who refused the HIV test is very rarely documented in the literature. During the course of the study, we could only include 62 women who had refused to be tested, for two reasons : first, the high level of HIV test acceptance (91\%) (Ekouevi et al., 2004). Second, the reluctance of the women who refused to be HIV tested to enter a survey, with a refusal rate of $70 \%$. It is possible that untested women who agreed to participate to our survey may be different from those who did not accept. Nevertheless, this small group of women, relatively homogenous, is very interesting per se: it reveals that there is a category of well educated, monogamous African women, used to talking about sexual risks with their partner and to using condoms, who refuse to be HIV tested. Moreover, despite their refusal to be tested, these women seem to have benefited from the HIV counselling provided during the pregnancy, since after this counseling, communication on STIs and HIV with their partner increased significantly and may be a first step on the way to adequate prevention. 
It seems important to conclude that PMTCT programs might play a role not only in the prevention of mother-to-child transmission of HIV, but also in the prevention of sexual transmission. For HIV-infected women, prenatal HIV-testing constitutes the entry point to appropriate access to HIV care for themselves and their relatives. Furthermore, for all women, irrespective of their HIV status and their acceptance of the testing, it is a unique opportunity in resource-limited countries to receive appropriate and efficient counselling on sexual risks and to introduce communication related to STIs and HIV within their couple. Our findings show that women, who have more contacts than men with health care services throughout pregnancy and children care, may act as intermediaries between their partners and the healthcare system. Counseling delivered within PMTCT programs should then particularly address spousal communication regarding sexual risks, as it seems to be an effective first step to prevention strategies to fight the AIDS epidemic in Africa. 
Table 1. Socio-demographic characteristics of women followed in the ANRS Ditrame Plus program after the offer of prenatal counselling and HIV testing, according to their acceptance of the HIV test and to their HIV status. Abidjan, Côte d'Ivoire. 2002-2005

\begin{tabular}{|c|c|c|c|c|c|}
\hline & \multicolumn{2}{|c|}{ Accepted prenatal HIV testing } & \multirow{2}{*}{$\begin{array}{c}\text { Refused } \\
\text { HIV-testing } \\
\text { HIV status } \\
\text { unknown } \\
(\mathrm{n}=52)\end{array}$} & \multicolumn{2}{|c|}{ Pearson $\chi^{2}$ test } \\
\hline & $\begin{array}{l}\text { HIV infected } \\
\quad(n=306)\end{array}$ & $\begin{array}{c}\text { HIV-negative } \\
(\mathrm{n}=352)\end{array}$ & & $\chi^{2} \#$ & $\chi^{2} \$$ \\
\hline \multicolumn{6}{|l|}{ Religion } \\
\hline Christian & 60.1 & 61.1 & 82.7 & & \\
\hline Muslim & 32.4 & 33.5 & 7.7 & 1.24 & $14.68 * *$ \\
\hline Other & 7.5 & 5.4 & 9.6 & & \\
\hline \multicolumn{6}{|l|}{ Education level } \\
\hline None & 27.8 & 29.8 & 7.7 & & \\
\hline Primary & 36.3 & 37.8 & 44.2 & 0.95 & $12.15^{* *}$ \\
\hline Secondary $-1^{\text {st }}$ cycle & 22.5 & 20.7 & 28.8 & & \\
\hline Secondary $-2^{\text {nd }}$ cycle & 13.4 & 11.7 & 19.3 & & \\
\hline Remunerated activity & 51.0 & 46.6 & 32.7 & 1.26 & 3.54 \\
\hline \multicolumn{6}{|l|}{ Age } \\
\hline $18-19$ & 4.6 & 8.8 & 7.7 & \multirow{5}{*}{$9.75^{*}$} & \multirow{5}{*}{0.80} \\
\hline $20-24$ & 27.8 & 34.4 & 36.5 & & \\
\hline $25-29$ & 39.9 & 32.7 & 36.5 & & \\
\hline $30-34$ & 19.3 & 16.7 & 13.5 & & \\
\hline 35 and above & 8.4 & 7.4 & 5.8 & & \\
\hline Polygamous union & 19.0 & 13.6 & 5.8 & 3.43 & 2.54 \\
\hline \multicolumn{5}{|l|}{ First sexual intercourse } & $4.22 *$ \\
\hline \multicolumn{6}{|l|}{ Housing } \\
\hline Individual & 36.6 & 42.6 & 51.9 & 2.47 & 1.60 \\
\hline Shared Housing ${ }^{a}$ & 63.4 & 57.4 & 48.1 & & \\
\hline
\end{tabular}

\#: comparison between HIV positive vs HIV negative ; $\$$ : comparison between HIV negative vs HIV unknown $* \mathrm{p}<.05, * * \mathrm{p}<.01$

a. Shared housing: typical housing with several houses organized around a yard where inhabitants live in crowded accommodation and share kitchen and restroom 
Table 2. Communication between women and regular partners regarding STIs and HIV and condom use, prior to and following prenatal HIV testing, according to the women acceptance of the HIV test and to their HIV status. Abidjan, ANRS DITRAME PLUS program, $2002-2005$.

\begin{tabular}{|c|c|c|c|}
\hline & \multicolumn{2}{|c|}{ Accepted prenatal HIV testing } & \multirow{2}{*}{$\begin{array}{l}\text { Refused HIV Testing } \\
\text { HIV status unknown } \\
(\mathrm{n}=52)\end{array}$} \\
\hline & $\begin{array}{l}\text { HIV infected } \\
\qquad(n=306)\end{array}$ & $\begin{array}{l}\text { HIV-negative } \\
\qquad(\mathrm{n}=352)\end{array}$ & \\
\hline Ever discussed STIs with their regular partner & $28.4 \%$ & $65.1 \%$ & $67.3 \%$ \\
\hline
\end{tabular}

\section{Following HIV testing ${ }^{2}$}

Discussed STIs with their regular partner

Comparison prior to/after HIV-testing (Mc Nemar test) :

Disclosed their HIV result to their partner

Suggested the partner to undertake HIV testing

Suggested the partner to use condoms in case of extra conjugal relationships

Used condoms with their partner after delivery

Comparison prior to/after HIV-testing (McNemar test) :

\section{$65.0 \%$}

$89.28 * *$

$42.8 \%$

$71.6 \%$

$58.2 \%$

$48.8 \%$

$39.84^{* *}$

\section{$96.6 \%$}

$103.42 * *$

$97.4 \%$

$96.6 \%$

$94.3 \%$

$58.7 \%$

$38.06^{* *}$
$90.4 \%$

$0.00^{(a) * *}$

$80.8 \%$ \#

$90.4 \%$

$92.3 \%$

$57.1 \%$

$0.75^{(a)}$ 
Notes (Table 2)

${ }^{1}$ Prior to HIV testing: within the two years preceding the pregnancy when they were offered HIV counseling and testing

${ }^{2}$ Following HIV testing: between offer of HIV counseling and testing and the 18 month post-partum.

\# informed the partner they were offered an HIV-test

$* \mathrm{p}<.05, * * \mathrm{p}<.01$

(a) : binomial distribution used 
Table 3. Logistic regression of the probability that the male partner was tested for HIV after the woman was offered antenatal counselling and HIV testing. Abidjan, Ditrame Plus, 2002-2005.

\begin{tabular}{|c|c|c|c|c|}
\hline \multirow{3}{*}{ Variable } & \multirow{3}{*}{ Modalities } & \multicolumn{2}{|c|}{ Frequency of partner HIV tested } & \multirow[b]{3}{*}[95\%\mathrm{CI}]{} \\
\hline & & & OR & \\
\hline & & $\%(\mathrm{n} / \mathrm{N})$ & & \\
\hline Woman suggested the partner & Yes & $19.8 \%(111 / 562)$ & 4.03 & {$[1.50-10.82]$} \\
\hline to undertake HIV testing & No & $8.0 \%(8 / 100)$ & 1 & - \\
\hline \multirow[t]{3}{*}{ Woman's HIV status } & Refused to be HIV tested & $6.0 \%(3 / 50)$ & 0.13 & {$[0.04-0.44]$} \\
\hline & HIV- & $13.3 \%(45 / 339)$ & 0.30 & {$[0.18-0.49]$} \\
\hline & $\mathrm{HIV}+$ & $25.4 \%(71 / 280)$ & 1 & - \\
\hline \multirow[t]{2}{*}{ Housing } & Shared $^{\mathrm{a}}$ & $21.0 \%(57 / 271)$ & 0.59 & {$[0.37-0.94]$} \\
\hline & Individual & $15.1 \%(60 / 396)$ & 1 & - \\
\hline Woman has a remunerated & Yes & $19.1 \%(61 / 319)$ & 1.54 & {$[0.96-2.48]$} \\
\hline activity & No & $16.6 \%(58 / 350)$ & 1 & - \\
\hline \multirow[t]{3}{*}{ Partner's age } & $20-29$ & $20.5 \%(25 / 122)$ & 1.45 & {$[0.74-2.85]$} \\
\hline & $30-39$ & $16.5 \%(51 / 310)$ & 0.86 & {$[0.50-1.49]$} \\
\hline & $40+$ & $19.3 \%(29 / 150)$ & 1 & - \\
\hline
\end{tabular}


Notes (Table 3):

- a : Shared housing: typical housing with several houses organized around a yard where inhabitants live in crowded accommodation and share kitchen and restroom

- Variables introduced in the model: woman's education level, partner's education level, type of union, woman's age, partner's age, woman's religion, woman's remunerated activity, woman's age at first sexual intercourse, individual housing or common courtyard, woman's HIV status, woman's discussion with the partner regarding her own HIV test, woman suggested her partner to undertake HIV testing. The model is a logistic regression with a stepwise descendant procedure. Only variables with $p<0.25$ in multivariate anaysis are presented.

- Women whose partner had been HIV tested before were excluded from the analysis $(\mathrm{n}=41)$. Logistic regression was performed among the women for whom the data on the partner's age and education level was available, i.e. 549 women. 
Table 4. Systematic condom use (\%) at sex resumption after delivery according to the women acceptance of the HIV test and to their HIV status. Abidjan, Côte d'Ivoire. 2002-2005.

\begin{tabular}{|c|c|c|c|c|c|c|c|c|c|}
\hline & \multicolumn{6}{|c|}{ Accepted prenatal HIV testing } & \multirow{2}{*}{\multicolumn{3}{|c|}{$\begin{array}{l}\text { Refused HIV Testing } \\
\text { HIV status unknown } \\
(\mathrm{n}=49)\end{array}$}} \\
\hline & \multicolumn{3}{|c|}{$\begin{array}{l}\text { HIV infected } \\
\quad(n=272)\end{array}$} & \multicolumn{3}{|c|}{$\begin{array}{l}\text { HIV-negative } \\
\quad(n=334)\end{array}$} & & & \\
\hline & $\%$ & $n / N$ & $\chi^{2}$ & $\%$ & $n / N$ & $\chi^{2}$ & $\%$ & $n / N$ & $\chi^{2}$ \\
\hline \multicolumn{10}{|l|}{ Religion } \\
\hline Christian & 39.8 & $66 / 166$ & \multirow{3}{*}{$\begin{array}{l}10.13 \\
* *\end{array}$} & 31.2 & $63 / 202$ & \multirow[t]{3}{*}{5.55} & 35.7 & $15 / 42$ & \multirow[t]{3}{*}{1.74} \\
\hline Muslim & 20.2 & $18 / 89$ & & 19.3 & $22 / 114$ & & 25.0 & $1 / 4$ & \\
\hline Other & 29.4 & $5 / 17$ & & 33.3 & $6 / 18$ & & 0 & $0 / 3$ & \\
\hline \multicolumn{10}{|l|}{ Education level } \\
\hline None & 18.9 & $14 / 74$ & \multirow{4}{*}{$\begin{array}{l}12.27 \\
* *\end{array}$} & 16.7 & $17 / 102$ & \multirow{4}{*}{$\begin{array}{l}14.98 \\
* *\end{array}$} & 25.0 & $1 / 4$ & \multirow[t]{4}{*}{0.75} \\
\hline Primary & 36.6 & $37 / 101$ & & 28.6 & $36 / 126$ & & 30.4 & $7 / 23$ & \\
\hline Secondary $-1^{\text {st }}$ cycle & 32.2 & $19 / 59$ & & 28.4 & $19 / 67$ & & 30.8 & $4 / 13$ & \\
\hline Secondary $-2^{\text {nd }}$ cycle and more & 50.0 & $19 / 38$ & & 48.7 & $19 / 39$ & & 44.4 & $4 / 9$ & \\
\hline None & 18.5 & $10 / 54$ & $6.90^{*}$ & - & $0 / 1$ & 0.38 & - & $0 / 2$ & 1.01 \\
\hline Discussed STIs with their regular partner & 37.4 & $68 / 182$ & $3.72 *$ & 27.6 & $90 / 326$ & 0.90 & 36.4 & $16 / 44$ & 2.70 \\
\hline Disclosed their HIV result to their partner & 36.8 & $39 / 106$ & 1.31 & 27.3 & $87 / 319$ & 0.01 & 39.0 & $16 / 41^{a}$ & $4.64^{*}$ \\
\hline Suggested the partner to undertake HIV testing & 38.2 & $76 / 199$ & $7.6^{* *}$ & 27.7 & $90 / 325$ & 1.21 & 33.3 & $15 / 45$ & 0.12 \\
\hline \multicolumn{10}{|l|}{ Partner HIV tested ${ }^{b}$} \\
\hline No & 27.4 & $51 / 186$ & $6.47^{*}$ & 27.3 & $76 / 278$ & 5.81 & 36.4 & $16 / 44$ & - \\
\hline Yes, HIV+ & 50.0 & $13 / 26$ & & - & $2 / 2$ & & - & & \\
\hline Yes, HIV- & 38.9 & $14 / 36$ & & 22.9 & $11 / 48$ & & - & & \\
\hline All & 32.7 & $89 / 272$ & & 27.2 & $91 / 334$ & & 32.6 & $16 / 49$ & \\
\hline
\end{tabular}


Notes (Table 4) : Only couples having resumed sex before the 18 months post-partum survey were considered

$* \mathrm{p}<.05, * * \mathrm{p}<.01$

a. For women who refused to be HIV tested, we consider here those who told their partner they were offered an HIV-test

b. Data on male partner HIV-testing was missing for 24 femmes HIV+ women, 6 HIV-women and 5 women who refused to be tested. 


\section{References :}

Allen, S., Meinzen-Derr, J., Kautzman, M., Zulu, I., \& Trask, S. (2003). Sexual behavior of HIV discordant couples after HIV counseling and testing. AIDS, 17(5), 733-740.

Babalola, S. (1999). Spousal communication and safe motherhood practices: evidence from the Tanzania 1996 DHS data. Paper presented at the third African Conference on Population, Durban, Republic of South Africa (RSA).

Becquet, R., Ekouevi, D. K., Viho, I., \& al., e. (2005). Acceptability of exclusive breastfeeding with early cessation to prevent HIV transmission through breastmilk, ANRS 1201/1202 Ditrame Plus, Abidjan, Côte d'Ivoire. Journal of AIDS, 40(5), 600608.

Bond, V., \& Dover, P. (1997). Men, women and the trouble with condoms: problems associated with condom use by migrant workers in rural Zambia. Health Transition Review, 7 Suppl, 377-391.

Brou, H., Agbo, H., \& Desgrees Du Lou, A. (2005). [Impact of HIV counseling and testing during antenal consultation for HIV- women in Abidjan (Cote d'Ivoire): a quantitative and qualitative study (Ditrame Plus 3 project, ANRS 1253)]. Sante, 15(2), 81-91.

Bühler, C., \& Kohler, H.-P. (2003). Talking about Aids : the influence of communication networks on individual risk perceptions of HIV/AIDS infection and favored protective behaviors in South Nyanza District, Kenya. Demographic Research, Special collection 1, art 13, 398-438.

Bunnell, R. E., Mermin, J. H., \& De Cock, K. M. (2006). HIV prevention for a threatened continent : implementing positive prevention in Africa. Journal of American Medical Association, 296(7), 855-858.

Chimbiri, A. M. (2007). The condom is an 'intruder' in marriage : evidence from rural Malawi. Social Science and Medicine, 64(5), 1102-1115. 
Cleland, J. G., Ali, M. M., \& Capo-Chichi, V. (1999). Post-partum sexual abstinence in West Africa: implications for AIDS-control and family planning programmes. AIDS, 13(1), $125-131$.

Dabis, F., Becquet, R., Ekouevi, D. K., \& al., e. (2005). Field efficacy of Zidovudine, Lamivudine and single-dose Nevirapine to prevent peripartum transmission of HIV. The ANRS 1201/1202 Ditrame Plus study, Abidjan, Cote d'Ivoire. AIDS, 19(3), 309318.

De Cock, K. M., \& Grubb, I. (2006). Towards universal access: WHO's role in HIV prevention, treatment and care. Bulletin of the World Health Organization, 84(7), 506.

Desgrees-du-Lou, A., \& Brou, H. (2005). Resumption of sexual relations following childbirth: norms, practices and reproductive health issues in Abidjan, Cote d'Ivoire. Reproductive Health Matters, 13(25), 155-163.

Desgrees-Du-Lou, A., Msellati, P., Viho, I., Yao, A., Yapi, D., Kassi, P., et al. (2002). Contraceptive use, protected sexual intercourse and incidence of pregnancies among African HIV-infected women. DITRAME ANRS 049 Project, Abidjan 1995-2000. International Journal of STDs and AIDS, 13(7), 462-468.

DiFranceisco Wayne, Pinkerton Steven, Dyatlov Roman, \& Geoffrey, S. (2005). Evidence of a brief surge in safer sex practices after HIV testing among a sample of High-risk men and women. Journal of AIDS, 39(5), 606-612.

Dodoo, F. N. (1998). Men matter : additive and interactive gendered preferences and reproductive behavior in Kenya. Demography, 35(2), 229-242.

Ekouevi, D. K., Leroy, V., Viho, I., \& al., e. (2004). Acceptability and uptake of a package to prevent mother-to-child transmission using rapid HIV testing in Abidjan, Cote d'Ivoire. $A I D S, 18(4), 697-700$. 
Ekouevi, D. K., Tonwe-Gold, B., \& Dabis, F. (2005). Advances in the prevention of motherto-child transmission of HIV-1 infection in resource-limited settings. AIDS Reader, 15(9), 479-480, 487-493.

Ezeh, A. C. (1993). The influence of spouses over each other's contraceptive attitudes in Ghana. Studies in Family Planning, 24(3), 163-174.

Gray, R. H., Li, X., Kigozi, G., Serwadda, D., Brahmbhatt, H., Wabwire-Mangen, F., et al. (2005). Increased risk of incident HIV during pregnancy in Rakai, Uganda: a prospective study. The Lancet, 366(9492), 1182-1188.

Hogsborg, M., \& Aaby, P. (1992). Sexual relations, use of condoms and perceptions of AIDS in an urban area of Guinea-Bissau with a high prevalence of HIV-2. In T. Dyson (Ed.), Sexual behaviour and networking : Anthropological and Socio-cultural studies on the transmission of HIV (pp. 203-231): Ordina Editions.

INS \& Macro Organization. (2001). Enquête démographique et de Santé, Côte d'Ivoire, 1998-1999. Calverton, Maryland, USA: INS et ORC Macro.

Kilewo, C., Massawe, A., Lyamuya, E., Semali, I., \& Kalokola, F. (2001). HIV counseling and testing of pregnant women in sub-Saharan Africa. Experiences from a study on prevention of mother-to-child HIV-1 transmission in Dar Es Salaam, Tanzania. Journal of AIDS, 28(5), 458-462.

Leroy, V., Van de Perre, P., Lepage, P., Saba, J., Nsengumuremyi, F., Simonon, A., et al. (1994). Seroincidence of HIV-1 infection in African women of reproductive age : a prospective cohort study in Kigali, Rwanda, 1988-1992. AIDS, 8(7), 983-986.

McIntyre, J. (2005). Sex, pregnancy, hormones, and HIV. The Lancet, 366, 1141-1142.

Medley, A., Garcia-Moreno, C., McGill, S., \& Maman, S. (2004). Rates, barriers and outcomes of HIV serostatus disclosure among women in developing countries: 
implications for prevention of mother-to-child transmission programmes. Bulletin of the World Health Organization, 82(4), 299-307.

Painter, T. M. (2001). Voluntary counseling and testing for couples: a high-leverage intervention for HIV AIDS prevention in sub-Saharan Africa. Social Science and Medicine, 53(11), 1397-1411.

UNAIDS. (2006). Report of the global AIDS epidemic, from www.unaids.org

Van Rossem, R., Meekers, D., \& Zkinyemi, Z. (2001). Consistent condom use with different types of partners: evidence from two Nigerian surveys. AIDS Education and Prevention, 13(3), 252-267.

Zamboni, B., Crawford, I., \& Williams, P. (2000). Examining communication and assertiveness as predictors of condom use : implications for HIV prevention. AIDS Education and Prevention (12), 492-504.

Zulu, E. M., \& Chepngeno, G. (2003). Spousal communication about the risk of contracting HIV AIDS in rural Malawi. Demographic Research, 1 Suppl, S1-S8.X 


\section{APPENDIX}

\section{Composition of the Ditrame Plus Study Group ANRS 1201/1202/1253}

\section{Bio-medical team :}

Principal Investigators: François Dabis, Valériane Leroy, Marguerite Timite-Konan, Christiane Welffens-Ekra. Coordination in Abidjan: Laurence Bequet, Didier K. Ekouevi, Besigin Tonwe-Gold, Ida Viho. Methodology, biostatistics and data management: Gérard Allou, Renaud Becquet, Katia Castetbon, Laurence Dequae-Merchadou, Charlotte Sakarovitch, Dominique Touchard. Clinical team: Clarisse Amani-Bosse, Ignace Ayekoe, Gédéon Bédikou, Nacoumba Coulibaly, Patricia Fassinou, Apollinaire Horo, Ruffin Likikouët, Hassan Toure. Laboratory team: André Inwoley, François Rouet, Ramata Touré. Psycho-social team: Hortense Aka-Dago, Alphonse Sihé. Scientific Committee: Stéphane Blanche, Jean-François Delfraissy, Philippe Lepage, Laurent Mandelbrot, Christine Rouzioux, Roger Salamon

\section{Social Science team :}

Principal Investigators: Annabel Desgrées-du-Loû, Benjamin Zanou, Coordination in Abidjan and quantitative survey: Hermann Brou, Qualitative survey : Annick Tijou-Traore, Hélène Agbo, Data Management : Gerard Djohan 


\section{ACKNOWLEDGEMENTS}

The primary sponsor of the ANRS 1201/1202/1253 Ditrame Plus study was the french Agence Nationale de Recherches sur le Sida et les hépatites virales (ANRS). Hermann Brou was a fellow of the ANRS. Renaud Becquet was a fellow of the French Ministry of Education, Research and Technology and of the French charity SIDACTION. Didier K. Ekouevi was fellow of the French charity SIDACTION.

We are indebted to the patients who participated in the ANRS 1201/1202/1253 Ditrame Plus study. We wish to thank the following for their invaluable assistance: Joanna Orne-Gliemann and Stephanie Robinson for translation and Nathalie Bajos, Caroline Moreau, Benoît Ferry and Emmanuel Lagarde for their helpful comments. 